\title{
LETRAMENTO CRÍTICO PARA DESMISTIFICAR CRENÇAS ACERCA DO ENSINO DE INGLÊS COMO LÍNGUA ADICIONAL
}

\author{
CRITICAL LITERACY TO DEMYSTIFY BELIEFS REGARDING TEACHING \\ ENGLISH AS AN ADDITIONAL LANGUAGE
}

Recebido: 30/10/2021

Aprovado: $24 / 11 / 2021$

Publicado: 22/12/2021

DOI: $10.18817 /$ rlj.v5i2.2699

\author{
Fátima Machado ${ }^{1}$ \\ Orcid ID: https://orcid.org/0000-0002-7974-2781 \\ Cassandra Rodrigues ${ }^{2}$ \\ Orcid ID: https://orcid.org/0000-0001-6423-5747
}

\begin{abstract}
RESUMO: Crenças podem ser sociais e individuais, paradoxais, contextuais e dinâmicas. No que tange o ensino de língua inglesa como língua adicional, ainda é flagrante a permanência de crenças impregnadas de preconceito linguístico e de ideologias epistemológicas colonialistas. Além de visões formalistas do que é língua que influenciam a expectativa sobre o que determina saber uma língua (por exemplo, domínio de formas e estruturas gramaticais negligenciando os aspectos sociocomunicativos), há também uma supervalorização de um modelo idealizado de falante "nativo" com um viés neocolonial que foca em variantes de prestígio (como o inglês americano ou britânico). Combater o preconceito linguístico, questionar as crenças do senso comum e fomentar o pensamento crítico ajuda a promover a autoestima e segurança linguística tanto de alunos quanto de professores. Este estudo, então, tem por objetivo selecionar as concepções de língua que nos parecem prejudiciais ao ensino do inglês como língua adicional a fim de demonstrar como tais concepções, em nome da objetividade científica, podem mascarar ideologias políticas colonialistas bastantes nocivas à prática docente. Propõe também uma desmistificação dessas crenças a partir dos multiletramentos e do letramento crítico como um caminho para uma formação linguística integral, consciente e crítica.
\end{abstract}

Palavras-chave: crenças; ensino de inglês; letramento crítico; multiletramentos.

ABSTRACT: Beliefs can be social and individual, paradoxical, contextual and dynamic. Regarding the teaching of English as an additional language, the permanence of beliefs filled with linguistic prejudice and colonialist epistemological ideologies is still evident. In addition to formalist views of what language is, which outlines what determines that one has knowledge of a language (for example, mastery of grammatical forms and structures disregarding or neglecting socio-communicative aspects), there is also an idealized model of a "native" speaker from a neocolonial perspective that focuses on certain variants (such as American or British English). Fighting linguistic prejudice, questioning common sense beliefs, and fostering critical thinking helps to promote self-esteem and language security for both students and teachers. This study, then, proposes a demystification of these beliefs based on the practice of multiliteracies and critical literacy as a path to a comprehensive, conscious and critical linguistic formation.

Keywords: beliefs; teaching English; critical literacy; multiliteracies.

\section{Introdução}

\footnotetext{
1 Aluna de mestrado do programa PPGL-Letras da Universidade do Estado do Rio de Janeiro, especialista em Linguística Aplicada ao Ensino de Inglês como Língua Adicional pela mesma universidade. E-mail: fatimamachado.rj@gmail.com

2 Aluna de mestrado do programa PPGL-Letras da Universidade do Estado do Rio de Janeiro, especialista em Linguística Aplicada ao Ensino de Inglês como Língua Adicional pela mesma universidade. Bolsita do programa CAPES. E-mail: rodriguescassandra21@gmail.com
} 
"O educador democrático não pode negar-se o dever de, na sua prática docente, reforçar a capacidade crítica do educando, sua curiosidade, sua insubmissão." (Paulo Freire)

Vivemos em "uma sociedade densamente multissemiotizada e marcadamente desigual" (ROCHA e MACIEL, 2013, p. 25). O olhar para o ensino de língua inglesa como língua adicional e as pesquisas relacionadas não podem estar desconectados e desassociados das questões sociais que envolvem linguagem, cultura, poder e educação. Não é possível dissociar o papel político e de resistência a discursos e forças hegemônicas de uma educação linguística que promova um movimento e exercício de deslocamento e ruptura (ROCHA e MACIEL, 2013).

Muitas de nossas crenças sobre a língua, sobre o que é saber uma língua e sobre quais maneiras seriam mais eficientes para se aprender uma língua adicional estão impregnadas de preconceito linguístico e de ideologias epistemológicas colonialistas. As crenças sempre fizeram parte da existência dos seres humanos, pois assim que começamos a pensar, começamos a crer em algo (BARCELOS, 2007) e podem ser entendidas como modos de pensamento, de construir a realidade, de perceber os fenômenos do mundo, "co-construídas em nossas experiências resultantes de um processo interativo de interpretação e (re)significação" (BARCELOS, 2006, p.18). Elas são, portanto, sociais e ao mesmo tempo individuais, paradoxais, contextuais e dinâmicas (BARCELOS, 2006, 2007).

É preciso primeiro, portanto, definir, ainda que de modo breve, o que algumas das principais correntes da linguística e seus mais influentes teóricos entendem por língua para identificar de que modo influenciam as crenças do senso comum, com o objetivo de demonstrar o que se pode afirmar cientificamente sobre a língua, o quanto as crenças se aproximam ou se afastam das concepções científicas e o quanto refletem pedagogias colonialistas de ensino de línguas. Não é nosso objetivo neste artigo realizar um inventário exaustivo a respeito dessas teorias linguísticas, mas selecionar as suas concepções de língua que nos parecem pertinentes ou prejudiciais à prática docente de línguas adicionais, em especial da inglesa.

Tampouco temos a menor pretensão de definir o que vem a ser determinada língua, mesmo porque, até hoje, não temos uma definição, que leve em consideração apenas critérios linguísticos, do que seria uma língua $x$, por exemplo, 0 inglês (RAJAGOPALAN, 1997). Nosso objetivo também é buscar demonstrar de que modo 
as certas concepções de língua mascaram ideologias políticas colonialistas bastante perigosas em nome da objetividade científica e da neutralidade do cientista (RAJAGOPALAN, 1997).

Pensamos que não há uma concepção de língua que seja intrinsecamente melhor ou pior do que outras, mas que há diversas concepções que apresentam diferentes valores ideológicos e que por isso podem ser mais ou menos adequadas ao ensino da língua inglesa (OLIVEIRA, 2014). Já que grande parte dos aprendizes de inglês deseja aprender a língua para usá-la nos mais diversos contextos sócioculturais de interação, as concepções formalistas (estruturalistas e gerativistas), que entendem a língua como um objeto homogêneo e autônomo, independente da situação comunicativa, não nos parecem as mais adequadas para o ensino de inglês, uma vez que não consideram os sujeitos usuários da língua e os usos que fazem dela, nem as variações linguísticas (OLIVEIRA, 2014; RAJAGOPALAN, 1997; WILSON, 2017).

Assim, o presente trabalho busca caminhos possíveis para desmistificar crenças acerca do ensino de inglês de forma a explorar uma formação linguística integral para que os alunos se tornem falantes competentes de uma língua amplamente usada no mundo sem que desconsiderem suas marcas de identidade socioculturais, reconhecendo-as como parte legítima (e não inferior) e integrante deste repertório linguístico e comunicativo. Para isso, exploramos como a pedagogia dos multiletramentos, "que busca negociar uma crescente variedade de linguagens e discursos" (ROJO, 2013, p. 7) ajuda a combater o preconceito linguístico e questionar as crenças do senso comum para fomentar o pensamento crítico e promover a autoestima e segurança linguística tanto de alunos quanto de professores.

\section{Como definimos uma língua/o que é saber uma língua?}

A língua pode ser entendida como uma forma de linguagem porque cria instrumentos que viabilizam o processo de comunicação entre os membros de uma comunidade linguística; um sistema de signos vocais ${ }^{3}$ usados pelos integrantes de um

$3 \quad$ Importante registrar que a língua dos sinais, usada pelos surdos, possui signos visuais e não vocais. Por apresentar características básicas das línguas naturais a maior parte dos autores considera o sistema de comunicação dos surdos uma língua, apesar de não ser constituído por sinais sonoros (CUNHA, COSTA, MARTELOTTA, 2017) 
grupo social como meio de comunicação (CUNHA, COSTA, MARTELOTTA, 2017). Já a linguagem é compreendida como uma habilidade, uma capacidade eminente e exclusivamente humana de se comunicar através de línguas (CUNHA, COSTA, MARTELOTTA, 2017). Usamos o termo língua para indicar "o conjunto de recursos fonomorfossintáticos e lexicais que, acionados pela semântica e pela pragmática, nós usamos para nossa interação sociocomunicativa com outros seres humanos e com o mundo" (BAGNO, 2015, p. 205).

A concepção estruturalista de língua, de base saussureana, a entende como um "sistema de signos que exprimem ideias" (SAUSSURE, 2006, p. 24) composto por estruturas gramaticais que se relacionam entre si e que são ordenadas por regras, desconsiderando o uso linguístico e as variações provocadas pelos usuários da língua em diferentes contextos sócio-culturais (OLIVEIRA, 2014). Para Saussure (2006) "a língua é [...] linguagem menos fala" (SAUSSURE, 2006, p. 92) porque a fala, ao contrário da língua, é individual, acessória, acidental, e por isso não pode constituirse em objeto de estudo científico (SAUSSURE, 2006). Sendo assim delimitada, a língua apresenta uma natureza homogênea, constituindo-se em um sistema de signos linguísticos em que, essencialmente, existe apenas a união de duas partes psíquicas: o sentido e a imagem acústica (SAUSSURE, 2006).

A Linguística Moderna, inaugurada por Saussure, é uma formação cultural e política especificamente européia, que concedeu caráter científico ao mito da língua nacional, isto é, de uma unidade linguística homogênea compartilhada pelos habitantes de um estado-nação, mito bastante em voga na virada do século $X X$, quando o conceito de langue foi criado (FAIRCLOUGH, 1996; PENNYCOOK, 2017).

Assim como Saussure, Chomsky também isolou "a língua daquilo que a torna um fenômeno social complexo" (OLIVEIRA, 2014, p.35). A partir dos conceitos de competência (conhecimento da língua) e desempenho (uso da língua) Chomsky focou na competência, definindo como objeto de estudo da linguística "o falante-ouvinte ideal que vive numa comunidade linguística completamente homogênea" (OLIVEIRA, 2014, p.35), pois "o uso que o falante-ouvinte faz da língua é um retrato imperfeito da sua competência devido à interferência de fatores psicológicos e físicos" (OLIVEIRA, 2014, p.35).

Ao excluir a fala e o uso de suas concepções de língua, apesar de seus propósitos científicos pertinentes e justificáveis, esses teóricos acabaram por realizar uma espécie de assepsia linguística bastante nociva para o ensino-aprendizagem de 
línguas, criando sérios problemas para a prática docente (OLIVEIRA, 2014). Afinal, como poderíamos pensar o ensino de línguas sem levar em conta seus usuários, os diversos usos que fazem da língua e as variações linguísticas? (OLIVEIRA, 2014).

Acreditamos que as variações linguísticas são fenômenos que constituem a língua e que sua própria existência depende da existência dos sujeitos que usam essa língua (OLIVEIRA, 2014), caso contrário a língua é considerada morta, como o latim (BAGNO, 2015). Do ponto de vista pedagógico, é necessário compreender a língua como interação social, "que coloca à disposição dos seus usuários um conjunto de estruturas gramaticais e de palavras para que eles possam interagir socialmente em encontros culturalmente marcados tanto na fala quanto na escrita" (OLIVEIRA, 2014, p.39), em que os elementos gramaticais não estão dissociados do uso da língua e dos diferentes significados que ajudam a produzir (OLIVEIRA, 2014).

Também acreditamos, como as correntes linguísticas formalistas, que a língua é sistema e estrutura; entretanto não compreendemos a língua como "um objeto autônomo, independente das intenções de uso, da situação comunicativa" (WILSON, 2017, p. 87, in Martelotta). Nossa concepção de língua tem uma perspectiva sociointeracionista e funcional, em que se faz necessário "observar as condições de uso da língua em situações reais de comunicação, [...] considerando [...] as relações entre forma e função, entre os fatores gramaticais e os sociais" (WILSON, 2017, p. 87, in Martelotta).

A língua, contudo, não é apenas um meio de comunicação: a língua é, antes de tudo, um dos atributos que constituem a identidade de um povo, uma nação, sendo, portanto, uma bandeira política (RAJAGOPALAN, 2003). Assim, as concepções formalistas de língua, que se baseiam em um falante ideal, puro, separado do mundo, isolado das interações sócio-culturais, acabam por criar um modelo irreal de falante perfeito da língua, que sempre utiliza a norma padrão, funcionando como uma espécie de alvo a ser alcançado pelos falantes reais da língua. Ainda que essa não tenha sido a intenção desses teóricos, ao separar a língua de sua materialidade linguística, de seus sujeitos reais que a falam de diversas maneiras, contribuíram para crença de que existe uma unidade linguística nas línguas, em que as variações são percebidas como erro, como uma falta de competência para usar determinada língua.

Ao buscar a homogeneidade e unidade da língua, o que essas correntes linguísticas privilegiam como objeto de estudo "são as instâncias de pureza e completude, seja a nível do indivíduo, seja a nível da comunidade de fala" 
(RAJAGOPALAN, 1997). Ao verificar que essa pureza não existe na realidade, invocase, em nome da ciência, a necessidade da homogeneização dos dados (leia-se higienização) (RAJAGOPALAN, 1997). "Homogeneidade é uma bandeira, por sinal a mesma que serviu a muitas ideologias fascistas ao longo da história da humanidade" (RAJAGOPALAN, 1997, p. 34), basta lembrar as atrocidades cometidas pelo nazismo em nome da "limpeza étnica" (RAJAGOPALAN, 1997).

Além disso, essas teorias instauraram a ideia do falante nativo como modelo de falante ideal de uma língua igualmente ideal que não existe na realidade linguística dos falantes reais. O falante nativo idealizado pela linguística estrutural seria uma espécie de "bom selvagem" rousseauniano, não contaminado pelo contato com outras línguas, um falante da língua "pura" cuja existência em nosso mundo globalizado, onde as línguas estão em contato umas com as outras, influenciando-se mutuamente, seria bastante remota (RAJAGOPALAN, 2003). Em oposição à figura do "bom selvagem" como falante nativo ideal, "o nativo que emergiu do modelo chomskiano foi um ser cartesianamente onipresente" (RAJAGOPALAN, 2003, p.68). Rajagopalan argumenta que o conceito atual de falante nativo é uma concepção ideológica neocolonialista que tem suas raízes na teoria linguística de Chomsky, para quem um falante nativo tem a competência perfeita simplesmente porque sabe sua língua e pronto, e que, portanto, seria o modelo a ser seguido (RAJAGOPALAN, 2003).

As concepções formalistas de língua como um objeto homogêneo, monolítico, falada por um "nativo" idealizado de uma comunidade linguística também idealizada têm fortes interferências nas crenças do senso comum, como veremos em seguida.

\section{Crenças sobre o aprendizados de línguas}

Nossas concepções sobre saber uma língua evidenciam o que acreditamos que uma língua é. Parece-nos bastante provável que a crença de que se o brasileiro não sabe nem português, portanto não pode aprender inglês, e de que saber uma língua é saber sua estrutura gramatical têm suas raízes nessas concepções formalistas de língua. Isso sugere uma visão multifacetada da língua, que seria homogênea e monolítica, sem relação com o contexto comunicativo.

Quando pensamos no ensino-aprendizagem de línguas adicionais, é bastante comum ouvir: "não sabe nem português, vai aprender inglês como?", para se referir a alunos que não dominam a norma padrão prescrita pela gramática normativa ou 
àqueles que utilizam variedades estigmatizadas da língua portuguesa. Tal declaração revela a crença de que saber uma língua é saber sua estrutura gramatical e que existe apenas uma língua que pode ser considerada correta. Ou seja, a língua se identifica com a gramática,indicando a crença em um unidade linguística imutável e invariável; não é pensada como um organismo vivo que sofre variações por parte de seus falantes ao longo do tempo.

Para Bagno (2015) declarações como a acima mencionada demonstram a confusão que as pessoas em geral fazem entre língua e gramática normativa e/ou variedades de prestígio. Logo, apenas os falantes que utilizam as variantes prestigiadas e/ou a norma padrão 4 sabem determinada língua. Contudo, como pode uma pessoa nascida no Brasil, em uma comunidade linguística falante de português, não saber a própria língua que fala? A crença na unidade linguística de uma língua implica pensar que a língua é monolítica, homogênea e imutável, assim os falantes de variedades estigmatizadas são percebidos como incapazes de falar essa língua padrão pura determinada pela gramática, dicionários, instituições de ensino e pela elite cultural. Ou seja, os falantes que não utilizam a norma padrão e/ou variedades prestigiadas sofrem preconceito linguístico, uma vez que são discriminados, inferiorizados e depreciados por seus modos de falar a língua (BAGNO, 2015; SCHERRE, 2008; VIANA, 2009).

O mito da unidade e homogeneidade linguística guarda relações com a concepção estruturalista da língua como um sistema autônomo, abstrato, fixo e invariável que se conecta com a ideia de língua nacional única e homogênea, falada por um grupo de pessoas igualmente homogêneo, nascida no período renascentista, com a formação dos estados-nação europeus (PENNYCOOK, 2017). Para o estadonação, que também é uma abstração política, a língua nacional promoveria a harmonia entre os indivíduos, transmitindo sensações de imobilidade e estabilidade (WALESKO, 2019). Assim, os indivíduos são socializados e educados na escola, tanto

4

É preciso diferenciar a norma padrão real, aquela usada pela elite cultural, pelos falantes de maior influência sociopolítica, da norma padrão referencial, uma espécie de norma ideal pertencente às gramáticas (BORTONI-RICARDO, 2021). Essa distinção entre norma padrão real e referencial (BORTONI-RICARDO, 2021), ou norma padrão e variedades prestigiadas (BAGNO, 2015) não ocorre na língua inglesa, já que o inglês padrão corresponde à variante de prestígio característica das classes dominantes (OLIVEIRA, 2014). As gramáticas da língua inglesa tendem a ser descritivas, isto é, descrevem a língua utilizada pela elite cultural (Crystal, Quirk, 1990), ao passo que as muitas gramáticas de português do Brasil tendem a prescrever uma norma que muitas vezes nem é utilizada por essa elite, sendo assim chamadas de normativas (BAGNO, 2015). 
na Europa quanto no $\mathrm{Brasil}^{5}$, em uma língua nacional oficial, ou seja, a norma padrão, que se pretende homogênea e que possui regras que devem ser respeitadas e cumpridas (WALESKO, 2019).

É preciso, portanto, compreender que a ideia de língua nacional, que traz consigo a crença na unidade e homogeneidade linguística, é uma questão política, histórica e ideológica que tem suas raízes nas formações dos estados-nação europeus, na industrialização e no colonialismo (PENNYCOOK, 2017). Ou seja, a concepção de língua como pertencente a uma nação, homogênea e imutável, que deve seguir certas regras gramaticais, é um acontecimento inscrito em certo espaçotempo: o surgimento dos estados-nação, que necessitavam uma língua para chamar de sua, expandir sua cultura e se imporem como potências colonialistas (PENNYCOOK, 2017; WALESKO, 2019).

O mito da homogeneidade linguística é legitimado com base em argumentos científicos positivistas: para que um objeto possa ser estudado, precisa ser sistematizado e para tanto, precisa ser homogêneo, abstraído do que nele varia, idealizado (OLIVEIRA, 2014; RAJAGOPALAN, 1997). Na prática, contudo, essa homogeneização da língua traduz-se, muitas vezes, em higienização, no sentido de "limpar a sujeira" do fenômeno da linguagem antes de analisá-la cientificamente (RAJAGOPALAN, 1997). A proposta da homogeneização linguística é uma questão político-ideológica; afinal, não pode ter sido mero acaso que o conceito de langue, tenha surgido em uma época em que o mito da "língua nacional" estava em seu ápice na virada do século XX (FAIRCLOUGH, 1996).

Além da confusão entre língua e norma padrão, tal crença pressupõe a existência de um português puro e ideal, o de Portugal, modelo de língua que deveria ser seguido pelos brasileiros, relacionando-se, portanto, com a crença de que apenas em Portugal se fala o português correto, de que os brasileiros não sabem a língua portuguesa (BAGNO, 2015)

Subjaz a todas essas crenças uma ideologia epistemológica colonialista, em que apenas o saber da Europa branca é válido, correto; outros saberes são percebidos como inferiores ao modelo eurocêntrico, evidenciando assim o mito da raça pura superior, a branca européia, e a crença de que a miscigenação da raça negra e

$5 \quad$ É salutar ressaltar que, embora o Brasil não seja monolíngue, do mesmo modo que os países europeus (e quiçá todos os países) não o são, somos politicamente considerados um país monolíngue, cuja língua nacional é o português (WALESKO, 2019). 
indígena, percebidas como "inferiores", acarreta uma espécie de atraso cognitivo na população brasileira que nos torna incapaz de sabermos falar o português que falamos (BAGNO, 2015).

Mas afinal, o que é saber uma língua? "Saber uma língua [...] significa conhecer intuitivamente e aplicar com facilidade e naturalidade as regras básicas de funcionamento dela" (BAGNO, 2015, p.58). Todo ser humano inserido em uma comunidade linguística adquire naturalmente o sistema linguístico dessa comunidade e é dele senhor absoluto (SCHERRE, 2008). Portanto, todo brasileiro que nasceu e cresceu em uma comunidade linguística falante de português, mesmo aqueles que não dominam a norma-padrão e utilizam as variedades estigmatizadas, sabem sim falar a língua portuguesa: apenas falam variedades diferentes, nem melhores nem piores. Não é por não dominar a norma-padrão que a pessoa não sabe português.

Contudo, tal concepção de saber uma língua não parece ser compartilhada pela maioria dos brasileiros. A crença em uma língua portuguesa homogênea falada por todos os portugueses, como se o português de Portugal não apresentasse variações como qualquer língua do mundo (BAGNO, 2015), reflete nas nossas crenças sobre aprender uma língua adicional. Logo, se acreditamos que nosso português é inferior, errado, uma corruptela; que deveríamos seguir nossa idealização de língua pura falada pelos brancos portugueses, como poderíamos aprender inglês, como poderíamos aprender outra língua se não sabemos nem a nossa própria? Sendo assim, acreditamos que para falar bem a língua inglesa é preciso falar como um "nativo", entendido como um falante monolítico, branco, das potências mundiais (Estados Unidos e Inglaterra), de classe média e com certo nível de instrução formal (CAMARGO, 2016).

Em sua pesquisa de mestrado, Barcelos (1995) identificou três crenças fortes de aprendizes sobre como aprender inglês: aprender a língua inglesa é adquirir itens gramaticais, a pressão do professor ou outro aspecto externo ao aluno como responsáveis pela aprendizagem, e a aprendizagem no país da língua-alvo como sendo a mais eficiente e rápida. No contexto brasileiro, duas crenças recorrentes de estudantes de Letras, verificadas em diversos estudos, são: a necessidade de viajar para o exterior para aprender inglês e a de falar como um "nativo" ao aprender uma língua adicional (BARCELOS, 2007).

Metade dos alunos entrevistados por Barcelos (1995) acredita que "aprender inglês é saber sobre a estrutura dessa língua e adquirir conhecimentos a esse 
respeito" (BARCELOS, 1995, p. 90). Para eles, aprender uma língua é internalizar o sistema dessa língua, conhecer sua estrutura linguística a fim de saber sua "forma correta" de falar e escrever, e como tal língua é usada pelos falantes de língua materna (BARCELOS, 1995). Isto é, aprender uma língua é aprender sua estrutura gramatical de acordo com o modo que os falantes dessa língua materna a utilizam. Essa crença na necessidade de aprender a gramática para se aprender uma língua condiz em parte com o que na linguística se entende por saber uma língua: é preciso sim aprender as estruturas gramaticais para aprender uma língua, entretanto, apenas saber estruturas gramaticais não é condição suficiente para que uma pessoa seja capaz de utilizar a língua nas mais variadas interações sócio-comunicativas (HYMES, 1994; OLIVEIRA, 2014). Segundo Dell Hymes (1994), existem regras de uso sem as quais as regras gramaticais seriam inúteis, logo, não basta saber as regras gramaticais, é preciso também saber usar tais regras, de acordo com as situações e necessidades socioculturais e interativas em que o falante se encontra no momento em que utiliza a língua (HYMES, 1994; OLIVEIRA, 2014).

É preciso investigar o que, no senso comum, entende-se por saber a gramática de uma língua. Franchi (2006) define a gramática como

[...] o conjunto de regras e princípios de construção e transformação das expressões de uma língua natural que as correlacionam com seu sentido e possibilitam a interpretação. Antes de ser um livro de etiquetas sociais ou um manual descritivo, a gramática é, de início, esse saber linguístico que todo falante possui, em um elevado grau de domínio e perfeição (FRANCHI, 2006, p. 99).

Essa concepção de gramática não parece equivaler às crenças do senso comum sobre saber a gramática de determinada língua. Acredita-se, pelo contrário, que o falante não possui esse saber linguístico, que ele precisa aprender gramática para adquirir esse saber, como se a língua fosse subordinada e dependente da gramática, "como se ela fosse uma espécie de fonte mística invisível da qual emana a língua "bonita", "correta" e "pura"”' (BAGNO, 2015, p. 94). A crença no mito de que para se saber uma língua é preciso saber sua gramática se conecta a confusão milenar que as pessoas geralmente fazem entre língua e gramática normativa, que acaba produzindo preconceito linguístico, pois aqueles que não sabem as regras da gramática normativa são percebidos como incapazes de usar sua própria língua, como se não soubessem falar a língua que falam (BAGNO, 2015). 
O apego ao ensino da gramática na tradição escolar da cultura ocidental remonta à Antiguidade Clássica: desde a queda do Império Romano até o fim da Idade Média o latim foi a única língua ensinada nas instituições educacionais, a língua da erudição (BAGNO, 2015; MARTELOTTA, 2017). Por ser a língua de poder usada pelas instituições religiosas, políticas, culturais e científicas da época, o latim converteu-se em objeto de veneração, em língua "perfeita" (BAGNO, 2015). Contudo, no final da Idade Média, o latim já havia se tornado língua morta, isto é, não era mais falado pelas pessoas, sem falantes que tivessem nascido e crescido em uma comunidade linguística que falasse a língua (BAGNO, 2015). Só era possível, portanto, aprender latim através de um processo de educação formal, das velhas gramáticas, que se converteram em instrumentos valiosos para aprender a língua.

Durante o Renascimento, época em que as grandes línguas nacionais floresceram, "os gramáticos de diferentes línguas tentam enquadrar seus idiomas nacionais nos moldes da gramática latina" (BAGNO, 2015, p.99). Aplicava-se, então, a metodologia de ensino do latim, língua morta, às línguas vivas nacionais: as aulas baseavam-se na análise sintática de frases sem contexto, que eram dissecadas em seus mínimos elementos e depois classificadas de acordo com a nomenclatura tradicional (BAGNO, 2015). A Gramática Tradicional, que teve a Gramática do Latim como fonte de inspiração, criou a norma padrão da língua por uma necessidade político-ideológica européia: a de unificar e homogeneizar a língua para assim unificar e homogeneizar seus povos, permitindo a expansão de suas culturas e a colonização de outros povos. Ao prescrever as normas gramaticais corretas, que se identificam com a língua utilizada pelos falantes de classes sociais privilegiadas, das grandes metrópoles, a Gramática Normativa abandona as formas que consideram erradas, excluindo formas que são usadas diariamente pelos falantes em suas interações comunicativas, adotando "uma visão parcial da língua, sendo incapaz de explicar a natureza da linguagem em sua totalidade" (MARTELOTTA, 2017, p.47).

Infelizmente, esse modelo de ensino de línguas parece perdurar até os dias de hoje, estando presente nas crenças das pessoas sobre o que é saber uma língua. $O$ ensino da nomenclatura tradicional, da análise de frase descontextualizadas, permite "aprender alguma coisa sobre a língua, mas não permite aprender a usar a língua" (BAGNO, 2015, p. 100); não permite desenvolver o conhecimento prévio que o aluno já tem do seu próprio idioma, aprender usos novos e diversos da língua que já domina (BAGNO, 2015). Estudos científicos da Linguística já provaram que ensinar a 
gramática normativa nos moldes da pedagogia clássica pouco contribui para a formação de "cidadãos capazes de ler e escrever com propriedade, eficiência, criatividade e segurança" (BAGNO, 2015, p. 101); ou seja, não contribui para o letramento crítico dos aprendizes, não forma o educando para além do "desempenho das destrezas" (FREIRE, 2019, p.14) preparando para atuarem como cidadãos participativos na sociedade onde vivem e promovendo oportunidades para articular a interação entre sujeito, cultura, identidade e língua de forma crítica (como veremos de forma mais detalhada na próxima parte).

Além de acreditarem que saber uma língua é saber sua gramática, a norma padrão da língua, esses alunos também crêem que é preciso falar como um "nativo" ao aprender uma língua adicional. O mito do falante "nativo" como modelo ideal de aprendizagem de uma língua não habita apenas o imaginário dos alunos, mas também de muitos professores e cursos de idiomas. No ensino de línguas adicionais, uma das metas dos esforços didáticos e metodologias de ensino tem sido levar o aprendiz ao nível de proficiência do "nativo", a aquisição de uma competência "perfeita", (CAMARGO, 2016, OLIVEIRA, 2014; RAJAGOPALAN, 2003) "entendendose por competência perfeita o domínio que o falante nativo supostamente possui da sua língua" (RAJAGOPALAN, 2003, p.67).

Essa crença é reforçada por diversos cursos de inglês, que oferecem professores "nativos" como uma grande vantagem e diferencial; como se, apenas por terem o inglês como língua materna, representassem o modelo autêntico da língua, puro e verdadeiro, sem marcas locais ou interferências de outras línguas (CAMARGO, 2016, OLIVEIRA, 2014). Muitos materiais didáticos de inglês também reforçam essas crenças, da unidade linguística e do "nativo" como falante ideal, ao estamparem as bandeiras dos Estados Unidos e/ou Inglaterra nas capas de seus livros, mencionando seguir a variante americana ou britânica, como se o inglês usados pelos falantes desses países fosse homogêneo e não apresentasse variações de classe social, etária, de gênero, regional, etc. (CAMARGO, 2016). Esse "nativo" branco, letrado, de classe média das potências mundiais, construído a partir de concepções colonialistas e eurocêntricas da língua, falaria a norma padrão da língua inglesa, ou seja, uma língua "pura" e "correta" que deveria ser imitada pelos falantes que almejam aprender inglês, caso contrário sofreriam preconceito linguístico. O próprio conceito de "nativo" falante da norma padrão não é ideologicamente inofensivo, porque implica um grau 
de "pureza" da língua, inatingível na realidade linguística dos falantes, que se identifica com uma "pureza" étnica nefasta e fascista (RAJAGOPALAN, 1997).

A norma padrão da língua, tanto da portuguesa como da inglesa, é algo bem distante da realidade linguística dos falantes dessas línguas. A norma padrão é um conceito puramente ideológico, abstrato, uma maneira que as classes dominantes têm de "controlar a diversidade sociocultural e de inculcar nas pessoas outra ideia puramente ideológica: a de que há variantes linguísticas erradas, pois existe apenas uma variante linguística correta." (OLIVEIRA, 2014, p.41). Em geral, a variante usada pelos grupos de maior prestígio sociopolítico torna-se a norma padrão[1], ou seja, é padronizada através das gramáticas e dicionários, passando a ser a língua ensinada nas escolas e a utilizada na literatura (BORTONI-RICARDO, 2021).

Desse modo, "qualquer atitude de valorizar uma variação em detrimento de outra implica critérios de natureza sociocultural, e não critérios linguísticos" (MARTELOTTA, 2017). Implica também, como buscamos demonstrar, critérios políticos e ideológicos colonialistas, impregnados de preconceito linguístico, racismo e xenofobia que se escondem sob o véu da cientificidade. Acreditamos que a pedagogia tradicional de ensino de línguas, seja materna ou adicional, baseada na memorização de regras gramaticais inúteis para a formação cidadã, em uma língua homogênea fictícia garantida pela norma padrão que não faz parte do uso real dos falantes, precisa ser substituída por uma pedagogia dos multiletramentos e letramento crítico, a fim de formar cidadãos que possam participar ativa e criticamente nas interações sócio-comunicativas.

\section{Multiletramentos e letramento crítico no ensino de inglês}

Considerando o status da língua inglesa, as novas formas de ler o mundo, a coexistência de múltiplas linguagens e mídias, nossa existência em espaços (físicos e digitais), a necessidade de se construir novos futuros sociais, propomos um olhar para a pedagogia dos novos letramentos a fim de destronar as crenças sobre as quais discorremos.

Desmistificar tais crenças (por exemplo, a de que saber uma língua está relacionado ao domínio de suas regras gramaticais ou a da superioridade do falante "nativo") é um desafio que se estende a alunos, pesquisadores, linguistas e professores de língua adicional. O cenário e contexto atual demandam habilidades 
que dialoguem com o desenvolvimento da capacidade de produzir e compreender textos que agreguem linguagens diferenciadas, ou seja, de múltiplos letramentos (ROJO, 2013, p. 8):

[...] as práticas de letramento contemporâneas envolvem: por um lado, a multiplicidade de linguagens, semioses e mídias envolvidas na criação de significação para os textos multimodais contemporâneos e, por outro, a pluralidade e a diversidade cultural trazidas pelos autores/leitores contemporâneos a essa criação de significação.

Kalantzis e al (2016) também apontam para necessidades mais abrangentes no que tange o ensino de uma língua adicional que transpassam uma visão monolítica e estrutural da língua, reforçando a importância da exploração da construção de significados que se relacionem com a ascensão da diversidade de um mundo globalizado e altamente interconectado; a urgência em se considerar variações linguísticas e a presença de um multilinguismo global; e a demanda de se promover espaços para diversidade e pluralidade cultural e linguística na sala de aula.

Ainda, Santos (2005, p.67) fala sobre "a possibilidade de engendrar o local com o global vem estruturando uma sociabilidade não mais fundada na noção de fixo e enraizado" e por isso, a formação dos alunos - inclusive e especialmente no ensino de inglês como língua adicional - precisa contemplar as práticas que já fazem parte de suas rotinas e que não negligenciem suas identidades nacionais e não gere relações hierarquizadas entre línguas e culturas em detrimento de um modelo de falante "nativo" idealizado.

Soares (2008, p.81) aponta que a definição de letramento crítico se traduz em "um conjunto de fatores que variam de habilidades e conhecimentos individuais a práticas sociais e competências funcionais e, ainda, a valores ideológicos e metas políticas". Então, pensando nas crenças que foram aqui colocadas, o enfoque nos multiletramentos, destacando o letramento crítico, se faz uma pedagogia necessária no ensino de língua inglesa para o alcance de um ensino de línguas que busque uma cidadania crítica e que pense o inglês como língua franca, isto é, uma língua que é utilizada como meio de comunicação por falantes de diferentes línguas maternas nos mais diversos tipos de interações sociocomunicativas.

O ensino de língua inglesa que contempla um letramento crítico irá propor problematizações como forma de impulsionar reflexões sobre a construção de 
sentidos e sobre o tecer relações discursivas sobre o outro e também sobre si nas interações comunicativas e nos processos de leitura (de textos e do mundo).

\section{Considerações Finais}

A crença na unidade linguística, representada pela norma padrão da língua, que por sua vez é prescrita pela Gramática Tradicional, cria, no imaginário coletivo, o mito do falante "nativo", branco, letrado, de classe média dos países mais influentes geopolítica, econômica e socioculturalmente no mundo. Esse falante "nativo" idealizado falaria sempre e somente a norma padrão da língua, algo que não condiz com a realidade linguística das interações sociocomunicativas desses mesmos falantes. Essas crenças têm suas raízes em correntes linguísticas que buscam a homogeneidade da língua em nome da cientificidade. Como buscamos demonstrar, ao isolar a língua do seu uso real e "higienizá-la", essas correntes da Linguística acabaram criando um "nativo" idealizado, falante de uma língua igualmente idealizada, que serve como modelo para o ensino-aprendizagem de línguas adicionais. As concepções de "nativo" e língua homogênea não são inocentes, contudo, e sim carregadas de ideologias políticas colonialistas e preconceituosas.

Uma perspectiva mais crítica e mais ampla, que englobe aspectos sociais, históricos e políticos, que não definam cultura por um viés superficial como "objeto estático, situado fora do tempo e do espaço" (BARBOSA, 2009, p.2), que não reproduza visões neocoloniais através das práticas de multiletramentos, especialmente de letramento crítico, são movimentos essenciais ao tratamos de uma língua usada globalmente como uma forma de buscar impacto social e cultural (res)significando então o papel do ensino de inglês como um ato político em busca de futuro global mais inclusivo, mais tolerante e com mais equidade.

\section{Referências}

BAGNO, M. Preconceito Linguístico. 56.ed. São Paulo: Parábola Editorial, 2015.

BARBOSA, L.M.A. "Visões interculturais ou identidades cristalizadas? O Brasil e os brasileiros nos livros didáticos de português para estrangeiros." In: Fleuri, R.M.(Org.). XII Congresso da Associação Internacional para pesquisa Intercultural (ARIC), v. 1, 2009, p. 1-18. 
BARCELOS, A.M.F. A cultura de aprender língua estrangeira (inglês) de alunos formandos de Letras. 1995. 200f. Dissertação (Mestrado em Linguística Aplicada) Universidade Estadual de Campinas, Campinas, SP.

BARCELOS, A.M.F. Cognição de professores e alunos: tendências recentes na pesquisa de crenças sobre ensino e aprendizagem de línguas. In: BARCELOS, A.M.F.; VIEIRA-ABRAHÃO, M. H. (Org.). Crenças e ensino de línguas: foco no professor, no aluno e na formação de professores. Campinas: Pontes, 2006. p. 15-41.

BARCELOS, A.M.F. Reflexões acerca da mudança de crenças sobre ensino e aprendizagem de línguas. Revista Brasileira de Linguística Aplicada, v. 7, n. 2, 2007.

BORTONI-RICARDO, S.M. Português brasileiro, a língua que falamos. São Paulo: Contexto, 2021.

CAMARGO, R. Uma Língua Inglesa para chamar de minha: equivocações sobre o bom falante de inglês. Revista Estudos Linguísticos, São Paulo, v. 45, n.2, p. 651-665, 2016.

CRYSTAL, D.; QUIRK, R. A Comprehensive Grammar of the English Language. 8. ed. New York: Longman Inc., 1990.

CUNHA, A.F.; COSTA, M.A.; MARTELOTTA, M.E. Linguística. In: MARTELOTTA, M.E. Manual de Linguística. 2. ed. São Paulo: Contexto, 2017. p. 15 - 30.

FAIRCLOUGH, N. Language and Power. 10.ed. New York: Longman Inc., 1996.

FREIRE, P. Pedagogia da Autonomia: saberes necessários à prática educativa. 60.ed. Rio de Janeiro / São Paulo: Paz e Terra, 2009.

FRANCHI, Carlos. Criatividade e Gramática. In: Mas o que é mesmo "gramática"? São Paulo. Parábola Editorial, 2006. p. 34-101.

HYMES, D. On communicative competence. (1972) In: J.B. Pride and J. Holmes (eds) Sociolinguistics: selected readings. Harmondsworth: Penguin, 1994. p. 269-293.

KALANTZIS, M; COPE, B.; CHAN, E.; DALLEY-TRIM, L. Literacies. Cambridge: Cambridge University Press, 2016.

MARTELOTTA, M.E. Conceitos de Gramática. In: MARTELOTTA, M.E. Manual de Linguística. 2.ed. São Paulo: Contexto, 2017. p. 44 - 70.

OLIVEIRA, L.A. Métodos de Ensino de Inglês: teorias, práticas, ideologias. 1.ed. São Paulo: Parábola Editorial, 2014.

PENNYCOOK, A. The cultural politics of English as an international language. New York: Routledge, 2017.

RAJAGOPLAN, K. Por uma Linguística Crítica: linguagem, identidade e a questão ética. São Paulo: Parábola Editorial, 2003. 
RAJAGOPLAN, K. A ideologia de homogeneização: reflexões concernentes à questão de heterogeneidade na linguística. Revista do Mestrado em Letras da UFSM, Santa Maria, n.14, p. 21-37, 1997.

ROCHA, C. H..; MACIEL, R. F. (orgs.). Língua estrangeira e formação cidadã: por entre discursos e práticas. Campinas: Pontes Editores, 2013.

ROJO, R. (Org.). Escol@ Conect@d@: os multiletramentos e as TICs. São Paulo: Parábola, 2013.

SANTOS, E. Educação online: cibercultura e pesquisa-formação na prática docente. $351 \mathrm{fl}$. Tese (Doutorado em Educação) - Faculdade de Educação da Bahia. Universidade Federal da Bahia, Salvador, 2005.

SAUSSURE, F. Curso de Linguística Geral. São Paulo: Cultrix, 2006.

SCHERRE, M. M. P.. Entrevista com Maria Marta Pereira Scherre sobre preconceito linguístico, variação linguística e ensino. [Entrevista concedida a] Jussara Abraçado. Cadernos de Letras da UFF - Dossiê: Preconceito linguístico e cânone literário. Niterói, n. 36, p. 11-26, 1. sem. 2008.

SOARES, M. Alfabetização e Letramento. 5.ed. São Paulo: Contexto, 2008.

VIANA, Nildo. Linguagem, discurso e poder: ensaios sobre linguagem e sociedade. Pará de Minas: Virtualbooks, 2009.

WALESKO, A.M.H. Formação inicial e o mito do "falante nativo": construções identitárias de professores de inglês em uma comunidade de prática. 2019. 317f. Tese (Doutorado em Letras) - Universidade Federal do Paraná, Curitiba, PR.

WILSON, V. Motivações Pragmáticas. In: MARTELOTTA, M.E. Manual de Linguística. 2.ed. São Paulo: Contexto, 2017. p. 87 - 110. 